Research Article

\title{
Dynamic Response Study of Impulsive Force of Debris Flow Evaluation and Flexible Retaining Structure Based on SPH-DEM-FEM Coupling
}

\author{
Bailong Li $\mathbb{D}$, ${ }^{1}$ Changming Wang $\mathbb{D}$, ${ }^{1}$ Yanying $\mathrm{Li}\left(\mathbb{D}\right.$, ${ }^{1}$ and Shuhua Zhang $\mathbb{D}^{2}$ \\ ${ }^{1}$ College of Construction Engineering, Jilin University, Changchun 130021, China \\ ${ }^{2}$ College of Information Communication, Changchun University of Technology, Changchun 130021, China
}

Correspondence should be addressed to Changming Wang; wangcm@jlu.edu.cn and Shuhua Zhang; zhangshuhua@ccut.edu.cn

Received 17 June 2021; Accepted 11 October 2021; Published 23 October 2021

Academic Editor: Xiaohu Zhang

Copyright (c) 2021 Bailong Li et al. This is an open access article distributed under the Creative Commons Attribution License, which permits unrestricted use, distribution, and reproduction in any medium, provided the original work is properly cited.

Flexible retaining structure is demonstrated to be an effective measure for debris flow prevention in mountainous areas, which can effectively separate water and stone, reduce particle mass, and dissipate kinetic energy. In order to explore the impulsive force and dynamic response of flexible retaining structure impacted by solid-liquid two-phase debris flow, a complex dynamic interaction model of particle-fluid-structure has been established by employing the SPH-DEM-FEM coupling numerical analysis method. In the present study, the process, impulse force, and dynamic response of a flexible retaining structure subjected to debris flow under different slopes were investigated, respectively. The numerical results are compared with those of the calculation formula of the peak impulsive force of the semiempirical debris flow. Meanwhile, the effectiveness of the coupling numerical simulation is verified. The simulation results show that the coupled SPH-DEM-FEM numerical analysis method can visualise the impact of the solid-liquid two-phase debris flow on the flexible retaining structure, reproducing the impact, retaining, water-stone separation, climbing, silting, and deposition process of debris flow. The dynamic time-history curve of the coupling numerical analysis method for the flexible retaining structure is consistent with the results of the existing literature. The debris flow evaluation results of flexible retaining structure impacted by solid-liquid two-phase debris flow are in an order of magnitude with the empirical formula results. Moreover, the results are reliable. The obtained results have a certain reference value for the study on the impulsive force and dynamic response of the flexible retaining structure impacted by solid-liquid two-phase debris flow and the engineering design of the flexible retaining structure.

\section{Introduction}

Debris flow is a solid-liquid two-phase mixed fluid containing a large number of rubbles and sediments, showing the movement characteristics of viscous laminar flow or dilute turbulent flow. It is the result of the combined action of topography, meteorology, hydrology, soil, and vegetation in the basin [1]. Debris flows are characterized by rapid flow velocity, large flow velocity, sudden eruption, and amazing destructive power. It is a special fluid-solid coupling material formed by rainfall confluence. Limited by a certain slope groove, it pours down to the accumulation area at a significantly fast speed, which can cause great damage to a variety of buildings along the way [2].
Debris flow disasters are extensively distributed around the world, while China is a mountainous country and the mountainous area accounts for approximately $69 \%$ of the total land area. The Tianshan Mountains, Kunlun Mountains, Himalayas, Qinling Mountains, Hengduan Mountains, and Changbai Mountains in China are all high-risk areas of debris flow. The total area of debris flow distribution is 4.3 million $\mathrm{km}^{2}$, of which 1.3 million $\mathrm{km}^{2}$ is an intense active area [3]. In China, there have been many major debris flow disasters, among which, the most notable one is the August 8 Zhouqu debris flow disaster in Gansu Province, with the severe consequences of 1,481 deaths, 1,824 injuries, 284 missing persons, and nearly 20,000 people affected [3]. The data show that debris flow 
composed of particles and fluids has great kinetic energy and impulsive force and can cause devastating damage to the structure [4].

Debris flow study is relatively complex, and previous studies are generally simplified into pure particle matter and fluid. For example, Ashwood and Hungr [5] used quartz sand and rubble for performing the physical simulation test to study the impact of debris flow. $\mathrm{Ng}$ [6] et al. studied the impact performance of dry sand and viscous fluid by the conducting centrifugal test. However, some scholars have studied the mixture of solid-liquid debris flow. Haas [7] et al. studied the solid-liquid mixture composed of rubble, sand, clay, and water. The results proved that the performance of solid-liquid mixture was significantly different from that of single-phase flow. The interaction between solid particles and fluid of debris flow would significantly change the movement characteristics and impulsive force of debris flow. It is challenging to describe and quantify the formation, movement, impact, and deposition process of solid-liquid two-phase debris flow due to solid-liquid interaction, which has always been the difficulty of study.

In addition to the formation, movement, impact, and deposition process of debris flow, the prevention and control measures of debris flow have also dominated a vital role in the protection of life and property [8-10]. As for the design of debris flow retaining structure, the impact of debris flow should be considered; otherwise, structural damage will be caused and the safety of life and property downstream will be seriously threatened [11-13]. The retaining structure can generally be divided into rigid retaining structure and flexible retaining structure [14], and the peak impulsive force of debris flow plays a key role in the design of retaining dam. At present, it is generally based on the fluid statics model, fluid dynamics model, or hybrid model [15]. In particular, the fluid dynamics model has been widely applied in engineering design due to the reliability of data. However, because of the different conditions, the value of empirical coefficient varies greatly among different scholars, seriously affecting the accurate prediction of the peak impulsive force of debris flow [16].

In recent years, the flexible retaining dam becomes increasingly popular because of its simple installation, high construction efficiency, good economy, and small impact on the environment [17]. Compared with the rigid retaining structure, the flexible retaining structure can generate large deformation under the impact, resulting in a better energy dissipation mechanism, thereby lowering the peak impulsive force [18]. However, the dynamic coupling among the particle-fluid flexible retaining structure is significantly complex, which depends on the hydrodynamic mechanism, the particle movement characteristics, and the deformation and mechanical characteristics of the flexible retaining structure, as well as the energy conversion and dissipation between them. It remains a highly challenging topic. At present, there is no reasonable theoretical basis for the design of flexible retaining structure. Therefore, a limited test and numerical simulation are carried out and the engineering is only designed and constructed by experience. Although the failure analysis of flexible retaining dam under debris flow impact is rarely discussed, this is the key issue of engineering design [19].
One of the main aspects of the study of the coupling effects of debris flow and flexible support structure is the numerical simulation method, which is mainly divided into continuous environment calculation method, discrete environment method, and mixed environment method $[17,20,21]$. The continuous environment calculation method relies on the continuous distribution of mass and deformation of the object under study. The equations describing the dynamic characteristics are established. These equations are discretized on the computational domain based on grids or particles and solved by combining the initial and boundary conditions $[18,22]$. The main continuous medium calculation methods are the finite element method and the smooth particle kinematics method, or in other words, both debris flow and flexible retaining structures are simulated by the finite element method or the SPH method. This method is more mature and has been verified in theory and experiment. The discrete medium method in the analysis of debris flow and flexible retaining structure is mainly the discrete element method [19, 23]. Leonardi et al. [24] employed the DEM method to study the coupling effect of debris flow and flexible retaining structure and compared with the experimental results. The results showed that the DEM method could better reflect the interaction between debris flow and flexible retaining structure and was close to the experimental results, thus verifying the effectiveness of numerical analysis method.

In order to make full use of the advantages of different methods, the coupling numerical analysis method of debris flow and retaining structure has become a research hotspot in recent years. Leonardi et al. [25-27] used the LBM-DEM method to address the effect of the debris flow on the structure and adopted the coupling numerical analysis method to conduct a series of analysis and numerical verification, proving the robustness of the method in various cases. The debris flow impact of different flexible retaining structures was carried out, and the failure mode of the flexible retaining structure was explored. $\mathrm{Li}$ and Zhao $[28,29]$ adopted the coupled CFD-FEM method to simulate the debris flow, as well as the impact on rigid and flexible retaining dams. The model revealed that the actual simulation of the debris flow needs to consider the solid-liquid interaction. In addition, the effect of erosion on the impulsive force of debris flow was taken into account. The results showed that the debris flow impulsive force was significantly influenced by the slope and the solid-liquid ratio. The impact law and failure mode of flexible retaining dam are studied by employing the coupling numerical analysis method. Liu et al. [30, 31], respectively, used SPHFEM and DEM-FEM to investigate the impact characteristics of debris flow, large stone, and retaining dam as well as the coupling effect of debris flow and flexible retaining structure. The results showed that the coupling numerical method could well reproduce the impact-climbing-silting process of debris flow and the impact issue of flexible retaining structure. Li et al. [32] used the SPH-DEM method to study the dynamic performance and impact force of debris flow on a rigid retaining structure. Although the coupling numerical analysis method provides the basis and 
reference for the theory and method of this paper, there is no research and discussion on the mechanical properties and impulsive force of flexible retaining structure. The flow process of debris flow is shown in Figure 1 [3].

In summary, there is no reasonable theoretical basis for the design of flexible retaining structure. Instead, the design and construction of the project only depend on experience, and no corresponding specification for the prevention and control of debris flow by flexible retaining dams has been formulated in various countries. There are very few research studies on dynamic response analysis of flexible retaining structure impacted by debris flow. Currently, the research only concentrates on the retaining structure affected by large rock, debris flow fluid, or debris flow fluid along with large rock. Only few numerical analysis methods are used to analyze the coupling effect of debris flow and flexible retaining structure. The SPH-DEM-FEM numerical analysis method is applied to investigate the dynamic response of a retaining structure impacted by debris flow here, providing a certain reference for debris flow prevention engineering practice.

\section{Numerical Calculation Theory}

LS-DYNA code is adopted for SPH-DEM-FEM numerical simulation, in which $\mathrm{SPH}$ is used to simulate liquid debris flow, DEM is used to simulate solid particles, and FEM is used to simulate flexible retaining structure and debris flow channel. The SPH-DEM-FEM coupling analysis method is adopted to establish a complex dynamic interaction model of particle-fluid-structure, which can truly simulate the dynamic interaction between actual debris flow and flexible retaining structure. The realization principle and control equations of numerical simulation are introduced in this chapter.

2.1. DEM Control Equation. Debris flow particles in the solid phase are modelled by DEM. An elastic model is adopted for the contact between solid-phase debris flow particles [33-36].

The expression of force on particles is shown as follows:

$$
\left.\begin{array}{l}
f_{n}=-\left(k_{n} \lambda+c_{n} v_{i j} \cdot n_{n}\right) n_{n} \\
f_{t}=-\left(k_{t} \delta+c_{t} s_{i j} \cdot n_{t}\right) n_{t}
\end{array}\right\} .
$$

Among which, $\lambda$ and $\delta$ represent the overlapping distances of normal direction and tangential direction, respectively, and $k_{n}$ and $k_{t}$ denote normal stiffness and tangential stiffness, respectively.

The resulting external force and the resulting external moment on the particles are expressed as follows:

$$
\left.\begin{array}{l}
F_{i}=\sum_{j=1}^{k}\left(f_{n i j}+f_{t i j}\right) \\
T_{i}=\sum_{j=1}^{k} r_{i}\left(f_{s i j} \cdot n_{t}\right)
\end{array}\right\} .
$$

Among which, $f_{s}$ represents the friction between particles.

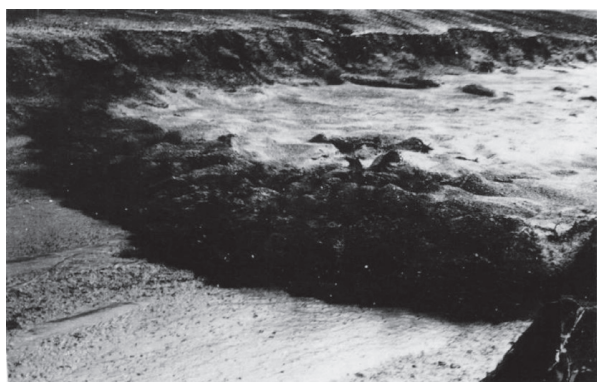

Figure 1: Dynamic process of debris flow [3].

An elastic material model is adopted for the interaction force between particles, and the constitutive model of the material is shown as follows:

$$
\sigma_{e}=E_{e} \varepsilon_{e} .
$$

Among which, $E_{e}$ represents the particle elastic model and $\varepsilon_{e}$ is the particle elastic strain.

2.2. SPH Control Equation. In this paper, SPH is used to simulate the flow of debris in the liquid phase. The basic concept of this method is to regard the fluid (or solid) as continuous one and describe it by interacting particle groups. Each particle point carries various physical parameters, including mass and velocity [37-40].

The approximate function of particles is shown in the following formula:

$$
\Pi^{h} f(x)=\int W(x-y) \mathrm{d} y,
$$

where $W$ is the kernel function.

Kernel function $W$ can be obtained by function $\theta$, and their relation is shown in the following formula:

$$
W(x, h)=\frac{1}{h(x)^{d}} \theta(x),
$$

where $d$ is the spatial dimension and $h$ is the smooth length that varies with time and space.

In this paper, the smooth kernel function is shown as follows:

$$
\theta(u)=C \times\left\{\begin{array}{l}
1-\frac{3}{2} u^{2}+\frac{3}{4} u^{3} ;|u| \leq 1, \\
\frac{1}{4}(2-u) 3 ; 1 \leq|u| \leq 2, \\
0 ; 2<\mid u /,
\end{array}\right.
$$

where $C$ is a generalized constant depending on the spatial dimension.

The SPH method bases on the integral formula of moving particles $\left(\left(x_{i}(t)\right)\right), i \subset\{1,2, \ldots, N\}$, among which $x_{i}(t)$ is the spatial position vector of particle $i$, which moves along the velocity field $v$. 
At this time, the approximation function of particle can be expressed by the following formula:

$$
\Pi^{h} f\left(x_{i}\right)=\sum_{j=1}^{N} w_{j} f\left(x_{i}\right) W\left(x_{i}-x_{j}, h\right),
$$

where $w_{j}=\left(m_{j} / \rho_{j}\right)$, and the gravity of the particle $w_{j}$ changes in proportion to the divergence of the fluid.

2.3. SPH-DEM-FEM Coupling Control Equation. The DEMFEM coupling equation is used to describe the complex dynamic interaction between solid-phase particles and a flexible containment structure, which can be found in the following equation $[18,41-43]$ :

$$
\begin{aligned}
& m_{i} \ddot{u}_{i}=m_{i} g+\sum_{k=1}^{m}\left(f_{n, i k}+f_{t, i k}\right)+\sum_{j=1}^{l}\left(f_{n, i j}+f_{t, i j}\right) \\
& I_{i} \ddot{\theta}_{i}=\sum_{k=1}^{m} T_{i k}+\sum_{j=1}^{l} T_{i j} \\
& M \ddot{X}+C \dot{X}+K X=f_{a}+f_{b}
\end{aligned}
$$

where $f_{n, i j}$ and $f_{t, i j}$ represent the normal and the tangential contact force.

The DEM-FEM coupling equation is shown as follows:

$$
M \ddot{U}+C U+K d=F+F_{C} .
$$

The SPH-DEM coupling control equation is used to describe the complex dynamic interaction between the particles in the solid phase of the debris flow and the fluid in the liquid phase of the debris flow [18], as presented in the following equation:

$$
\left.\begin{array}{rl}
m_{i}^{s} \frac{d u_{i}^{s}}{d t} & =F_{i}^{c}+F_{i}^{b s}+m_{i}^{f} f_{i}^{f s} \\
I_{i}^{s} \frac{d \omega_{i}^{s}}{d t} & =M_{i}^{c}+M_{i}^{f s}+M_{i}^{b s} \\
\frac{d u_{i}^{f}}{d t} & =-\sum_{j=1}^{N} m_{j}\left(\frac{p_{i}}{\rho_{i}^{2}}+\frac{p_{j}}{\rho_{j}^{2}}+\Pi_{i j}+R_{i j} f_{i j}^{4}\right) \nabla_{i} W_{i j}+f_{i}^{s f}+f_{i}^{b f}
\end{array}\right\}
$$

where $F_{i}^{b s}$ and $F_{i}^{b s}$ are the force on each other and $M_{i}^{f s}, M_{i}^{b s}$, and $M_{i}^{c}$ denote the torque.

\section{Calculation Model}

This paper selects Nanjiaogou as the prototype. The rugged topography in the ditch is sharp, the gullies can be found anywhere, and the slope of the main ditch formation area is $19^{\circ} \sim 47^{\circ}$, which belong to a vast debris flow ditch. The detailed geological information of Nanjiaogou can be found in [32].

In order to study the impulsive force and dynamic response of flexible retaining structure impacted by debris flow, a complex dynamic interaction model of particle-fluid- structure is established in the present study. Considering that the debris flow impulse force and the dynamic response of the flexible retaining structure are mainly studied in this paper and the actual gully is basically in trapezoidal distribution, to facilitate the study, the debris flow gully is simplified into trapezoidal one, and retaining and governance measures are performed on the main gully formation area with the steep slope. Considering that the slope of the main ditch formation area is $19^{\circ} \sim 47^{\circ}$, the average slope of the main gully formation area is confirmed at $30^{\circ}$. In this paper, the impulsive force and dynamic response of flexible retaining structure are analyzed, when the slope of gully is $15^{\circ}, 20^{\circ}, 30^{\circ}, 40^{\circ}$, and $50^{\circ}$.

3.1. Geometric Model. The geometric model of the debris flow is shown in Figure 2, and the geometric model of the flexible retaining structure is presented in Figure 3. The specific parameters of the geometric model are displayed in Table 1. The parameters such as debris flow channel and DEM particle density, elastic modulus, and Poisson's ratio are shown in the literature [32], and the specific mechanical parameters of the flexible retaining net and support cable are shown in the literature $[24,28,29]$.

The research object of this paper is mainly the impact force and dynamic response of the flexible retaining structure. Then, according to the field survey, the channel is roughly trapezoidal distribution and the bottom and the side of the gully are then simplified into the trapezoidal section according to the on-site situation. Furthermore, in view of the fact that the slope of the main ditch formation area is $19^{\circ} \sim 47^{\circ}$, the average value $30^{\circ}$ is selected; debris flow is composed of solid particles and fluids, which impacts the flexible retaining structure under the action of gravity, reproducing scenery of the impact, blocking by the flexible retaining structure, climbing along the flexible retaining structure, and water-rock separating in the process of impacting by debris flow. And this paper studies the impulsive force and dynamic response of flexible retaining structure impacted by solid-liquid two-phase debris flow.

The flexible retaining structure consists of flexible retaining nets and support cables. The four support cables are numbered as NO.1, NO.2, NO.3, and NO.4 from the bottom to top. The distance between the support cables is $0.5 \mathrm{~m}$. The geometric model of the flexible retaining structure is shown in Figure 3. With a diameter of $20 \mathrm{~mm}$, the flexible retaining net is formed by steel wires winding. The hexagonal side length of the retaining net is $0.1 \mathrm{~m}$, which can smoothly discharge debris flow and effectively prevent debris flow particles from flowing out. The support cable is formed by a steel wire winding with a diameter of $20 \mathrm{~mm}$, having an equivalent diameter of $0.1 \mathrm{~m}$. The flexible retaining net and the supports cable are fixedly connected to bear the force in a better way. The specific mechanical parameters of the flexible retaining net and support cable are shown in the literature $[24,28,29]$.

3.2. Constitutive Model of Materials. Because the channel rock mass in this paper relatively remains stable, the debris flow channel is simulated by rigid shell material. In this 


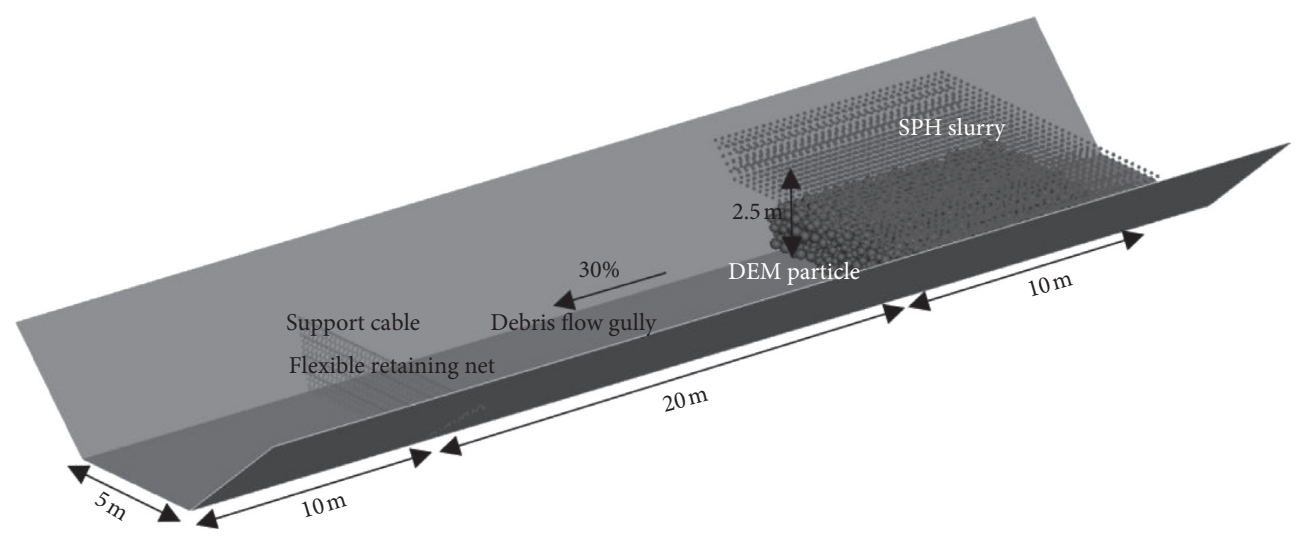

Figure 2: Geometric model of debris flow.

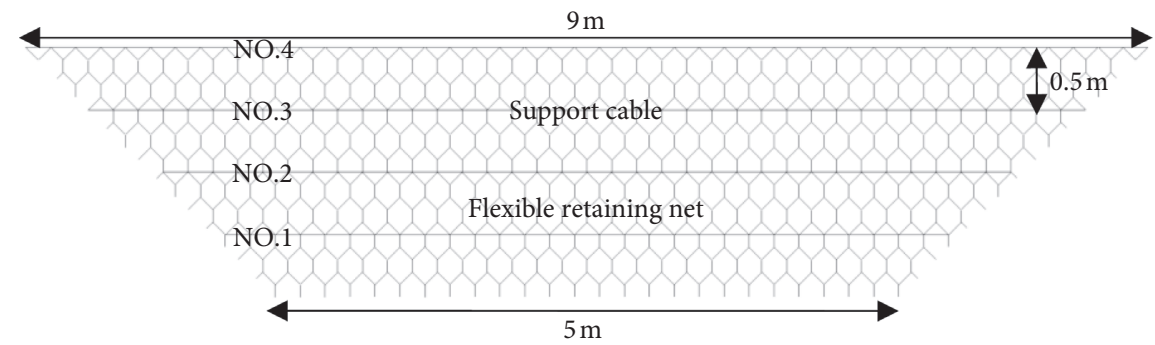

FIgURE 3: Geometric model of flexible retaining structure.

TABLE 1: Basic setting parameters of simulation.

\begin{tabular}{lcccccc}
\hline & $\begin{array}{c}\text { Density } \\
\left(\mathrm{kg} / \mathrm{m}^{3}\right)\end{array}$ & $\begin{array}{c}\text { Elastic modulus } \\
(\mathrm{GPa})\end{array}$ & $\begin{array}{c}\text { Poisson's } \\
\text { ratio }\end{array}$ & $\begin{array}{c}\text { Yield strength } \\
(\mathrm{MPa})\end{array}$ & $\begin{array}{c}\text { Ultimate } \\
\text { strain }\end{array}$ & Constitutive model \\
\hline Channel & 3000 & 30.0 & 0.24 & - & - & RIGID \\
$\begin{array}{l}\text { DEM particles } \\
\text { Flexible retaining }\end{array}$ & 2650 & 30.0 & 0.30 & - & - & ELASTIC \\
$\begin{array}{l}\text { net } \\
\text { Support cable }\end{array}$ & 7850 & 177 & 0.30 & 1770 & 0.05 & PLASTIC_KINEMATIC \\
\hline
\end{tabular}

paper, the RIGID material model is adopted, with 6056 shell elements in total. The parameters of debris flow channel adopt the numerical simulation parameters in the literature [19].

According to the field sampling test, the measured average density of solid particles in debris flow source is $2650 \mathrm{~kg} / \mathrm{m}^{3}$. Based on the field survey and laboratory test, we measured that the particle size range of provenance is $0.2 \sim 0.4 \mathrm{~m}$. The size range of DEM particles set by us is consistent with the field test results. The solid-liquid ratio of debris flow exerts a great influence on the characteristics of debris flow. In this paper, the ratio of solid to liquid is 1:1. This paper uses discrete element particle simulation. The LSDYNA ELASTIC model is adopted for the material constitutive, the LS-DYNA DE_BY_PART contact model is adopted for the interaction between the particles, and the LSDYNA DE_SURFACE_COUPLING model is used for the contact between the particles and the channel. In addition, the LS-DYNA DE_TO_BEAM_COUPLING model is used for the contact between particles and flexible retaining structure, with a total of 2236 particles in the abovementioned models.

The object of this paper is the low-speed moving dilute debris flow, without considering the effect of viscous force for the time being. The density of water is $1000 \mathrm{~kg} / \mathrm{m}^{3}$, and the friction force between fluids is 0.12 . The value of friction coefficient will be described in detail in Section 3.3. The SPH model is used for analysis, and the constitutive model employs the NULL material model, with the viscosity coefficient of 0.001 . The constitutive model of water is involved in this paper, while the constitutive model uses the EOS_MURNAGHAN model, and the constant of state equation GAMMA is 7.0 , with $K_{0}$ of 150,000 . To sum up, there are totally 4351 particles in the model. The SPH_DE_COUPLING contact model is adopted for the interaction between SPH particles and DEM particles, and the AUTOMATIC_NODES_TO_SURFACE model is adopted for the contact between SPH particles and channels. The parameters of fluids adopt the numerical simulation parameters in the literature [19]. 
The support cable of flexible retaining structure is modelled by cable element, with the density of $7850 \mathrm{~kg} / \mathrm{m}^{3}$ and yield strength of $1770 \mathrm{MPa}$. Because the flexible retaining structure bears the dynamic impact, the material constitutive model adopts the PLASTIC_KINEMATIC model, with the ultimate strain of 0.05 . The flexible retaining net is simulated by BEAM element, with the density of $7850 \mathrm{~kg} / \mathrm{m}^{3}$ and yield strength of $1380 \mathrm{MPa}$. Because the flexible retaining structure bears the dynamic impact, the constitutive model of the material adopts the PLASTIC_KINEMATIC model. The specific mechanical parameters of flexible retaining nets and support cables can be found in the literature $[24,28,29]$.

3.3. Boundary Conditions. The channel and the flexible retaining structure are firmly connected with the ground. The bottom and both sides of the debris channel are completely fixed and capped. The flexible retaining net and the supporting cable are connected with the ground through the anchor cable. Therefore, the flexible retaining net and support cables are fully fixed in this paper.

The coefficient of friction between debris flow solids is typically $0.1-0.5$ [16-18] by analyzing and comparing the experimental and simulation results in a large amount of relevant literature. According to similar studies, the trialand-error method is generally used to explore and compare the numerical simulation results with actual cases. When the peak velocity data of debris flow numerical simulation are close to the experimental or actual data, the parameters are regarded to be more accurate. After adopting the trial-anderror method and reviewing similar literature, it can be found that the simulated results are close to the actual results, when the coefficient of friction between the debris flow solids and the channel and the retaining wall is 0.3 and the coefficient of friction between the debris flow fluid and the channel and the flexible retaining structure is 0.12 .

We use the dynamic explicit method of LS-DYNA code for performing the analysis. The analysis step time is $10 \mathrm{~s}$. The debris flow begins to slide with an initial velocity of $0 \mathrm{~m} /$ $\mathrm{s}^{2}$. The gravitational acceleration of both the debris flow fluid and the debris flow solid particles is $9.8 \mathrm{~m} / \mathrm{s}^{2}$. Totally, the calculation gets 1974743 incremental steps. The CPU time is $22 \mathrm{~h} 3 \mathrm{~min} 43 \mathrm{~s}$.

\section{Establishment of Calculation Model}

4.1. Impacting Process. The impact, retaining, water-rock separation, and deposition process of flexible retaining structure impacted by debris flow are shown in Figure 4. When $t=0.9 \mathrm{~s}$, the debris flow starts to move, and at this time, "dragon head, dragon body, and dragon tail" have basically taken shape. Debris flow fluid and solid particles yield complex dynamic coupling interaction. When $t=2.3 \mathrm{~s}$, the solid-liquid two-phase debris flow reaches the bottom of the flexible retaining structure. At this moment, the maximum velocity of debris flow reaches $10.52 \mathrm{~m} / \mathrm{s}$, and the particle-fluid-structure joint is forced to produce complex dynamic interaction and impact the flexible retaining structure. Meanwhile, the "dragon head" of debris flow impacts the flexible retaining structure, climbing high and separating water-rock, and the solid particles remain at the bottom of the retaining structure under the action of retaining structure. At the same time, most of the fluid is discharged from the retaining structure. When $t=3.5 \mathrm{~s}$, the "dragon body" impacts the flexible retaining structure. Most of the debris flow solid particles are retained at the bottom, and the fluid is discharged. The debris flow will continue to impact the flexible retaining structure. At this time, because of the climbing effect, the bottom of the flexible retaining structure produces a dead load due to particle deposition, while the top part is still impacted by the dynamic impact of the debris flow. The SPH method can greatly deal with the splash and diffusion of fluid particles and participate in complex dynamic interaction with flexible retaining structure and debris flow particles. The numerical simulation well reflects the complex dynamic interaction of particle-fluidstructure. When $t=5.2 \mathrm{~s}$, the debris flow silts back and the particles finally deposit at the bottom of the retaining dam to produce a dead load. The fluid is slowly discharged.

4.2. Climbing and Silting Process. The climbing and silting process of the flexible retaining structure impacted by debris flow is illustrated in Figure 5. When $t=2.5 \mathrm{~s}$, debris flow particles reach the bottom of the flexible retaining structure and start to impact the debris flow retaining dam and climb high. At this time, the water-rock separation has already taken shape and the fluid is discharged through the retaining structure. The flexible retaining structure is deformed. Besides, the most deformed parts are the middle and bottom of the flexible retaining structure. When $t=3.0 \mathrm{~s}$, debris flow particles continue to climb high and some even silt back in certain part. At this time, it can be observed that particlefluid-structure shapes complex dynamic interaction, and the current climbing height is $1.3 \mathrm{~m}$. When $t=3.5 \mathrm{~s}$, the "dragon body" impacts the retaining dam, and the debris flow particles climb to the highest level, with obvious back silting and particle splashing. The climbing height is as high as $2.1 \mathrm{~m}$. When $t=5.2 \mathrm{~s}$, the debris flow silts back, finally producing a dead load at the bottom of the retaining dam. At this moment, the height of silting is the height of the retaining structure.

4.3. Analysis of Displacement Change of Flexible Retaining Structure over Time. The displacement change over time in the middle position of four support cables (NO.1, NO.2, NO.3, and NO.4) of flexible retaining structure under different slopes is monitored in Figure 6. The results reveal that when the slope is 50 degrees and $t=3 \mathrm{~s}$, the displacement of the middle position of NO.4 support cable of flexible retaining structure reaches the maximum, and the maximum value is $0.265 \mathrm{~m}$. Then, it decreases rapidly to $0.160 \mathrm{~m}$ after reaching the peak value. When the slope is 15 degrees, 20 degrees, 30 degrees, and 40 degrees, the peak displacement value of the middle position of the support cable of the flexible retaining structure is $0.0283 \mathrm{~m}, 0.071 \mathrm{~m}, 0.164 \mathrm{~m}$, and $0.221 \mathrm{~m}$, respectively. Subsequently, all decrease to dead 


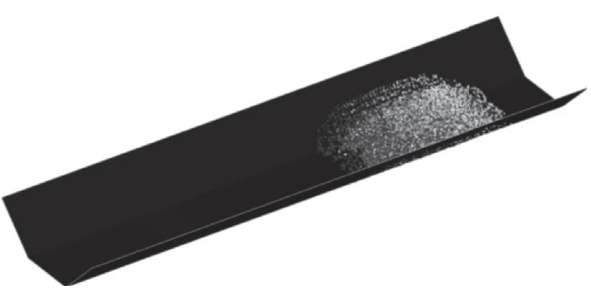

(a)

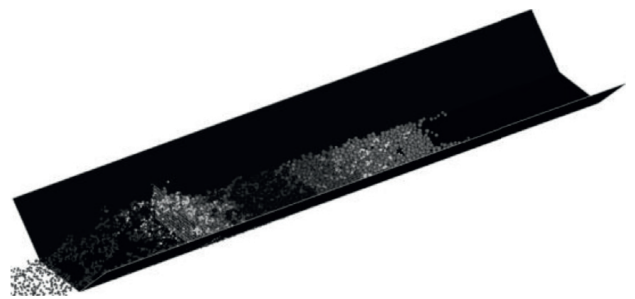

(c)

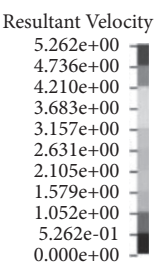
$9.943 \mathrm{e}+00$ $8.949 \mathrm{e}+00$ $7.954 \mathrm{e}+00$ $6.960 \mathrm{e}+00$ $5.966 \mathrm{e}+00$
$4.971 \mathrm{e}+00$ $4.971 \mathrm{e}+00-$
$3.977 \mathrm{e}+00$ $2.983 \mathrm{e}+00$ $1.989 \mathrm{e}+00$ $9.943 \mathrm{e}-01$

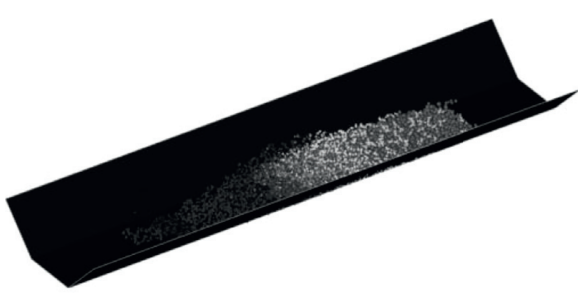

(b)

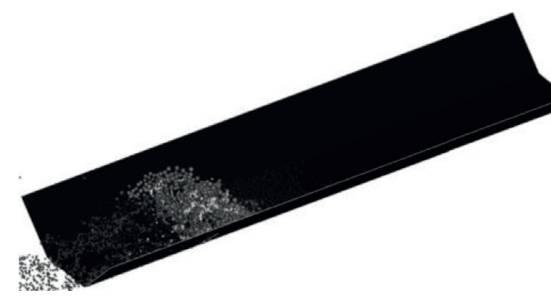

(d)
Resultant Velocity $1.052 \mathrm{e}+01$
$9.468 \mathrm{e}+00$ $9.468 \mathrm{e}+00$
$8.416 \mathrm{e}+00$ $7.364 \mathrm{e}+00$ $6.312 \mathrm{e}+00$ $5.260 \mathrm{e}+00$ 5.208e+00 $3.156 \mathrm{e}+00$ $2.104 \mathrm{e}+00$ $1.052 \mathrm{e}+00$ $0.000 \mathrm{e}+00$

Figure 4: Process of flexible retaining structure impacted by debris flow. (a) $t=0.9 \mathrm{~s}$. (b) $t=2.3 \mathrm{~s}$. (c) $t=3.5 \mathrm{~s}$. (d) $t=5.2 \mathrm{~s}$.

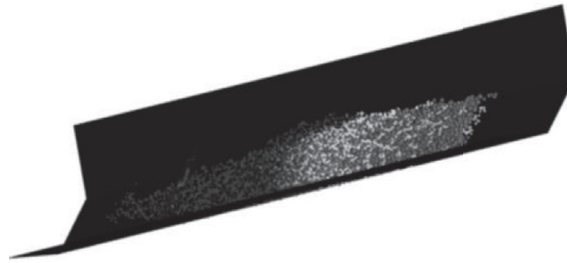

(a)

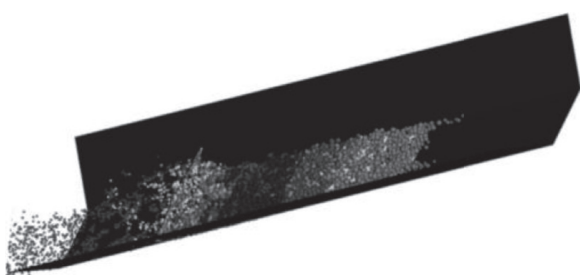

(c)

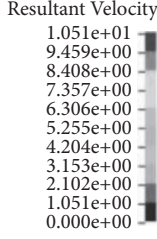

Resultant Velocity $9.943 \mathrm{e}+00$ $8.949 \mathrm{e}+00$ $7.954 \mathrm{e}+00$ $6.960 \mathrm{e}+00$
$5.966 \mathrm{e}+00$ $5.966 \mathrm{e}+00$ $4.971 \mathrm{e}+00$
$3.977 \mathrm{e}+00$ $3.983 \mathrm{e}+00$
$2.983 \mathrm{e}$ $1.989 \mathrm{e}+00$ $9.943 \mathrm{e}-01$
$0.000 \mathrm{e}+00$

Figure 5: Climbing and silting process of debris flow.

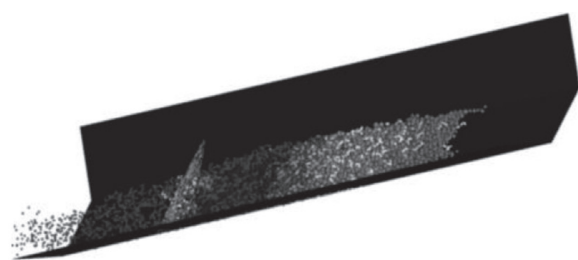

Resultant Velocity $1.023 e+01$
$9.207 e+00$ $8.184 \mathrm{e}+00$ $7.161 \mathrm{e}+00$ $6.138 \mathrm{e}+00$ $5.115 \mathrm{e}+00$ $4.092 \mathrm{e}+00$
$3.069 \mathrm{e}+00$ $3.069 \mathrm{e}+00$ $2.046 \mathrm{e}+00$ $1.023 \mathrm{e}+00$
$0.000 \mathrm{e}+00$

(b)

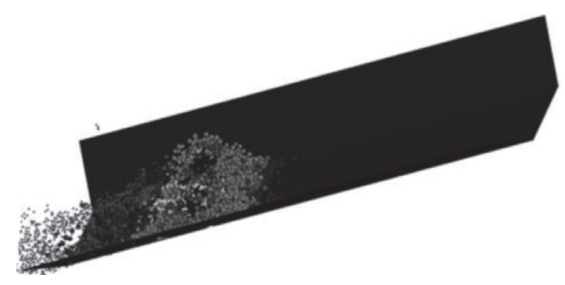

Resultant Velocity $6.842 \mathrm{e}+00$ $6.158 \mathrm{e}+00=$ $4.789 \mathrm{e}+00$ $4.789 \mathrm{e}+00$
$4.105 \mathrm{e}+00$ $4.105 \mathrm{e}+00$
$3.421 \mathrm{e}+00$ $2.737 \mathrm{e}+00$ $2.053 \mathrm{e}+00$ $1.368 \mathrm{e}+00$ $6.842 \mathrm{e}-01$

(d)

(a) $t=2.5 \mathrm{~s}$. (b) $t=3.0 \mathrm{~s}$. (c) $t=3.5 \mathrm{~s}$. (d) $t=5.2 \mathrm{~s}$.

displacement, which are $0.0146 \mathrm{~m}, 0.055 \mathrm{~m}, 0.122 \mathrm{~m}$, and $0.170 \mathrm{~m}$, respectively. When the slope is $15^{\circ}, 20^{\circ}, 30^{\circ}, 40^{\circ}$, and $50^{\circ}$, the difference between the maximum peak displacement and static displacement of the flexible barrier structure is $0.0137 \mathrm{~m}, 0.016 \mathrm{~m}, 0.042 \mathrm{~m}, 0.051 \mathrm{~m}$, and $0.105 \mathrm{~m}$, respectively. Moreover, the simulation results are identical to the numerical simulation and test results performed by Leonardi et al. [24-27], showing that the above method is suitable for simulating the flexible retaining structure impacted by debris flow.

4.4. Analysis of Impulsive Force Change over Time. The impulsive force change of flexible retaining structures with different slopes $\left(15^{\circ}, 20^{\circ}, 30^{\circ}, 40^{\circ}\right.$, and $\left.50^{\circ}\right)$ over time is displayed in Figure 7. It can be observed from the figure that when the slope is 50 degrees and $t=2.9 \mathrm{~s}$, the impulsive force of the debris flow on the retaining dam reaches its peak value, which is $6089 \mathrm{kN}$, and then decreases rapidly to $3832 \mathrm{kN}$. When the slope is $15^{\circ}, 20^{\circ}, 30^{\circ}$, and $40^{\circ}$, the peak values of impulsive force of the retaining dam are $987 \mathrm{kN}, 1983 \mathrm{kN}$, $3690 \mathrm{kN}$, and $4625 \mathrm{kN}$, respectively, and subsequently all decrease to dead loads. With the increase of the slope, the start time of the debris flow impact force is $3.4 \mathrm{~s}, 3.2 \mathrm{~s}, 3 \mathrm{~s}, 2.5 \mathrm{~s}$, and $2 \mathrm{~s}$, respectively. In addition, the peak time of the debris flow impact force is $4.9 \mathrm{~s}, 4.7 \mathrm{~s}, 3.9 \mathrm{~s}, 3.2 \mathrm{~s}$, and $2.9 \mathrm{~s}$, respectively.

We compare the numerical calculation results according to the semiempirical formula of impulsive force peak value of the debris flow based on hydrodynamic theory proposed by Kwan [44]:

$$
F_{\max }=\kappa \rho v^{2} h_{0} w \sin \beta,
$$

where $\kappa=a \mathrm{Fr}^{b}$ is the dynamic pressure coefficient, $\rho$ represents the density, $v$ is the impulsive velocity, $w$ is the width, and $h_{0}$ is the height of debris flow. 

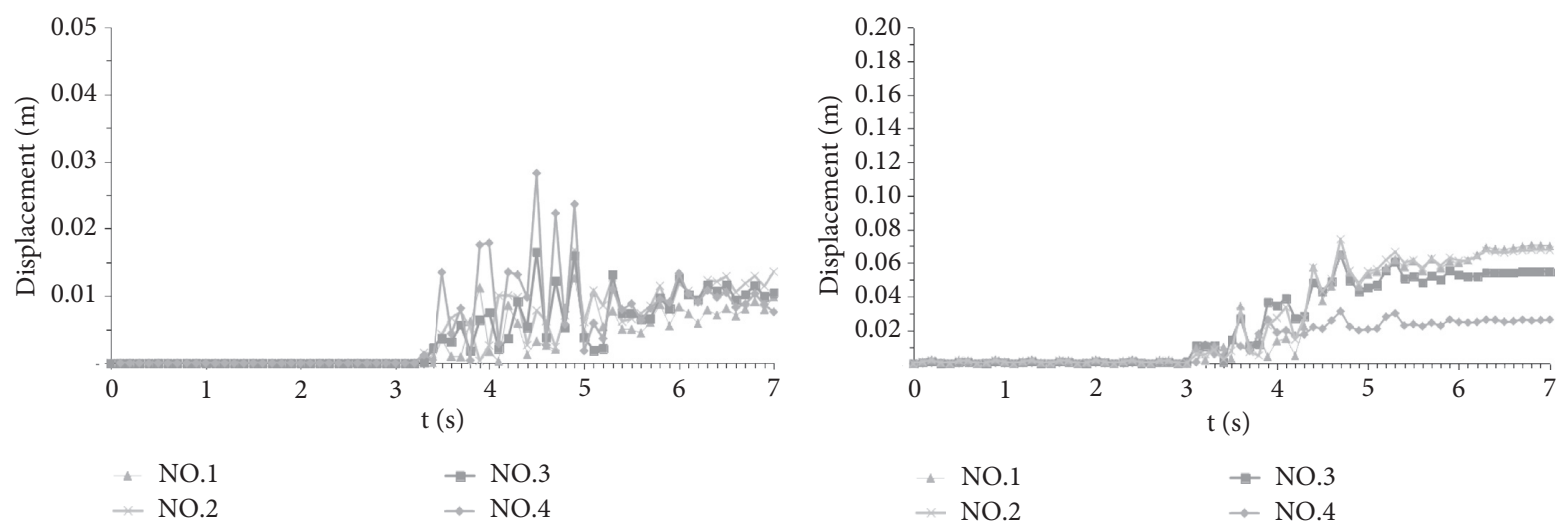

(a)

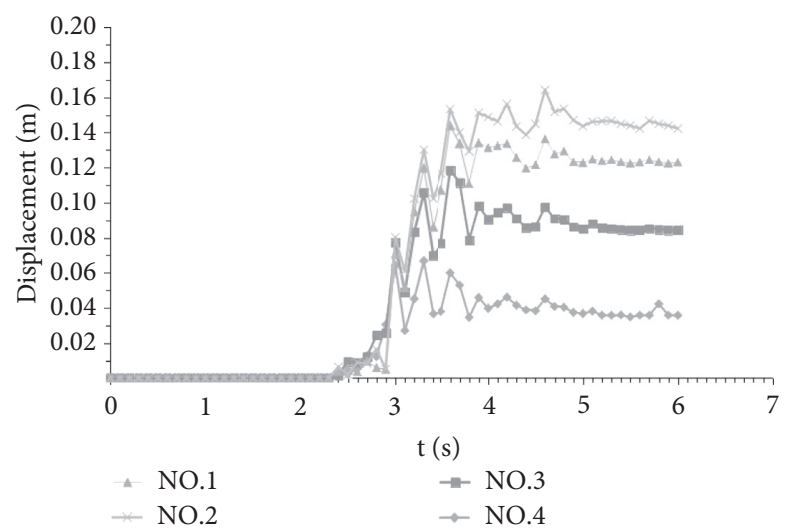

(c)

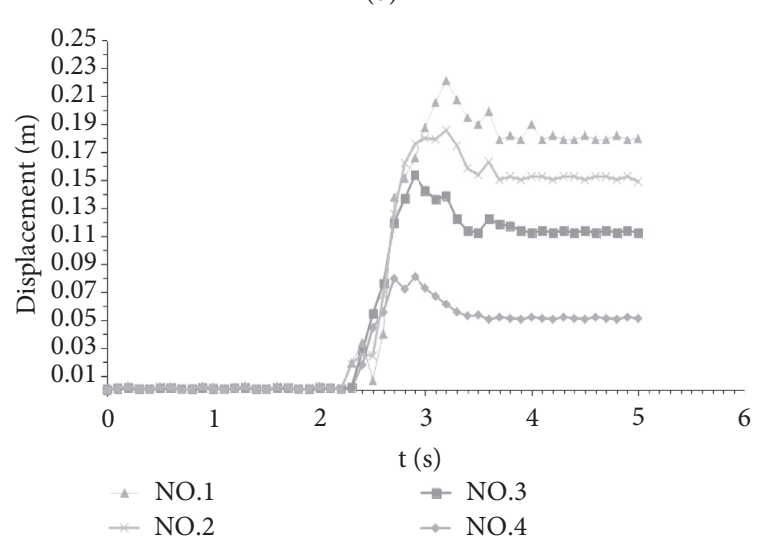

(d)

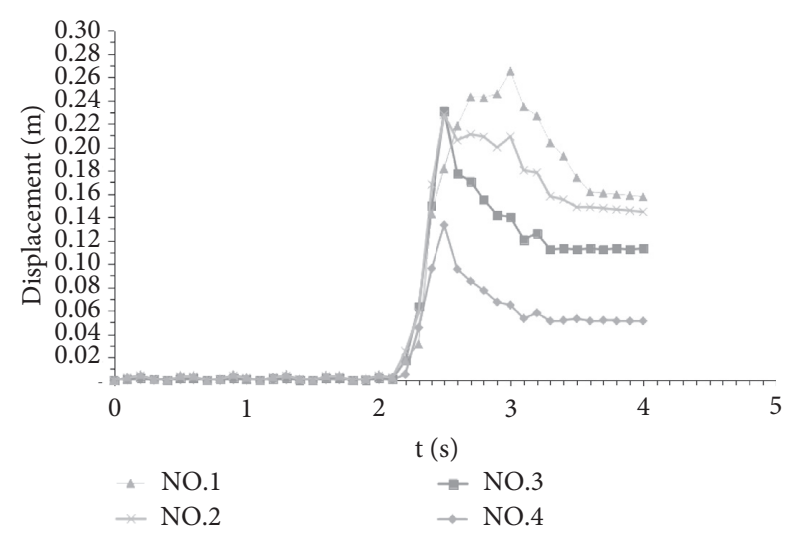

(e)

FIGURE 6: Analysis of the displacement change on the monitoring point of the flexible barrier structure over time. (a) 15 degrees. (b) 20 degrees. (c) 30 degrees. (d) 40 degrees. (e) 50 degrees.

The calculation results are obtained from the numerical calculation method in this paper, and the existing empirical formulas are shown in Table 2. The calculation error ranges from $12.1 \%$ to $27.4 \%$. Comparing the numerical calculation method adopted in the present study with the empirical values, the impulsive force results of the two methods are relatively close. However, the empirical methods do not consider the water-rock separation and the complex dynamic interaction of particle-fluid-structure. Therefore, the numerical analysis method is more reasonable than the empirical methods.
4.5. Maximum Deformation of Flexible Retaining Structure. The maximum deformation of flexible retaining structure with different slopes $\left(15^{\circ}, 20^{\circ}, 30^{\circ}, 40^{\circ}\right.$, and $\left.50^{\circ}\right)$ can be found in Figure 8. The maximum deformation of flexible retaining structure is positively associated with the channel slope, and the maximum deformation position is located in the middle of flexible retaining structure, which is consistent with the observed results in practice. When the slope is $15^{\circ}, 20^{\circ}, 30^{\circ}$, $40^{\circ}$, and $50^{\circ}$, the maximum peak displacement values in the middle of the flexible retaining structure are $0.0283 \mathrm{~m}$, 


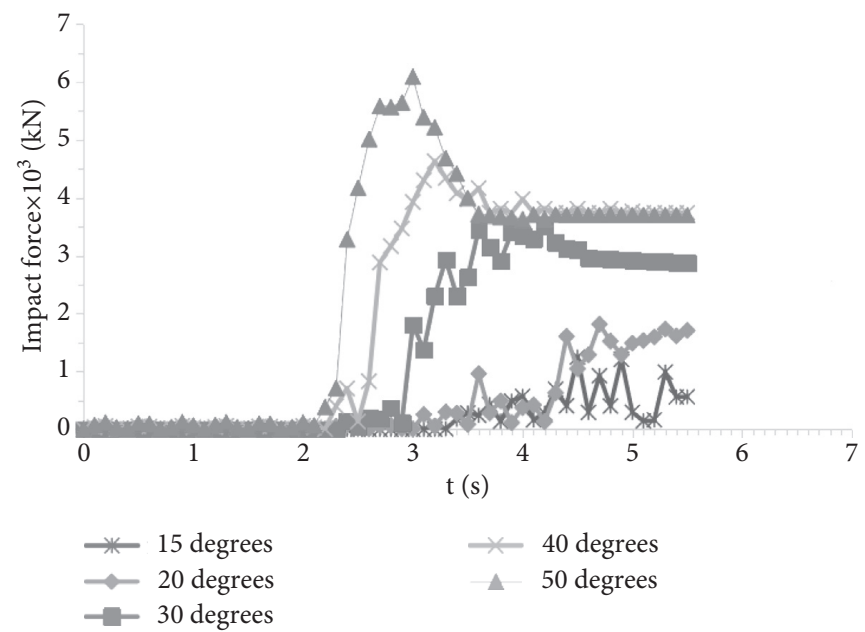

Figure 7: Analysis of impulsive force change of flexible retaining structure over time.

TABLe 2: Comparison of maximum impact force.

\begin{tabular}{|c|c|c|c|c|c|}
\hline & $15^{\circ}$ & $20^{\circ}$ & $30^{\circ}$ & $40^{\circ}$ & $50^{\circ}$ \\
\hline Kwan empirical value $(\mathrm{kN})$ & 1359 & 2532 & 4516 & 5409 & 6927 \\
\hline Method adopted in this paper $(\mathrm{kN})$ & 987 & 1983 & 3690 & 4625 & 6089 \\
\hline Error $(\%)$ & 27.4 & 21.7 & 18.3 & 14.5 & 12.1 \\
\hline
\end{tabular}
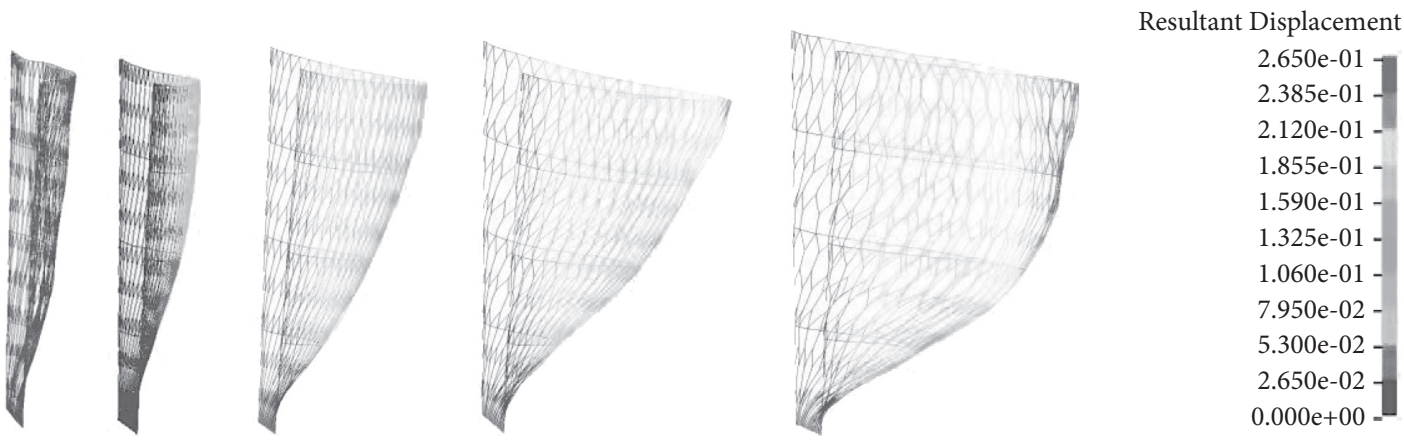

Figure 8: Maximum deformation of flexible retaining structure.

$0.071 \mathrm{~m}, 0.164 \mathrm{~m}, 0.221 \mathrm{~m}$, and $0.265 \mathrm{~m}$, respectively. Clearly, it can be seen that the support cable can restrain the flexible retaining net from deformation. Because the flexible retaining net and the supporting cables are fixed to each other, the deformation of the two is consistent with each other. In addition, the deformation of the flexible retaining net between the supporting cables is bigger than the deformation of the supporting cable, showing a convex shape.

\section{Discussion}

According to the results, the SPH-DEM-FEM coupling numerical analysis method vividly simulates the complex dynamic interaction of particle-fluid-structure, reproducing the impact, retaining, water-stone separation, climbing, silting, and deposition process of debris flow. The SPH method can greatly handle the splashing and diffusion of fluid particles and participate in complex dynamic interaction with flexible retaining structure and debris flow particles. The water-stone separation phenomenon can well reproduce the real debris flow blocking process, which is difficult to be reflected by other numerical analysis methods, which can also build up a good foundation for better evaluating the accuracy of debris flow impact assessment of flexible retaining structure. The displacement change of flexible retaining structure over time is analyzed here. Moreover, the simulation results and laws are consistent with the existing research results.

The analysis of impulsive force change over time is carried out. Although the analysis results are similar to the existing empirical formula, the empirical formula does not consider the water-rock separation and the complex dynamic interaction between particle-fluid-structure, and the error between the numerical simulation results and the empirical formula ranges from $12.1 \%$ to $27.4 \%$. Therefore, the numerical analysis method is more reasonable than the empirical method. The peak impulsive force of debris flow is positively correlated with the slope of the channel, and the 
larger the slope is, the greater the peak impulsive force of debris flow is. Then, the impulsive force of debris flow is decreased to a dead load, with enormous decrease in amplitude. When the slope is small, the peak impulsive forces of debris flow are close to a dead load. The impulsive force of debris flow will decrease slowly in the later stage, which is caused by the fluid removal from the flexible retaining structure due to the water-rock separation. It cannot be presented by employing the empirical formula method and traditional numerical analysis method. The results of the coupled numerical analysis method are more convincing than the empirical formula method.

The maximum deformation of flexible retaining structure is analyzed, and the deformation is positively associated with the slope of the channel. This is because when the slope of the channel is sharp, the gravitational potential energy of debris flow is relatively large, and once the debris flow takes shape, the kinetic energy and impulsive force produced by debris flow will be far greater than when the slope is small. $\mathrm{Li}$ et al. [32] explore the impulsive force and dynamic performance of rigid retaining structure impacted by debris flow by adopting the SPH-DEM-FEM method. By comparing impulsive force and dynamic performance of flexible retaining structure impacted by solid-liquid two-phase debris flow discussed in this paper, the dynamic performance and impact characteristics of flexible retaining structure and rigid retaining structure are quite different. Because of the water-rock separation and the remarkable ability to absorb energy, the impulsive force of the flexible retaining structure is much smaller than that of the rigid retaining structure. This also indicates that the traditional impulsive force formula of debris flow is not applicable to the flexible retaining structure, which is also the research significance of the present study. The results show that the mechanical performance of flexible retaining structure is more reasonable than that of rigid retaining structure.

Since the rigidity of the flexible retaining structure is much smaller than that of the rigid retaining structure, the dynamic characteristics between them are significantly different. The displacement change over time between the flexible retaining structure and rigid retaining structure is different by two orders of magnitude. The recovery ability after deformation of the flexible retaining structure is far less than that of the rigid retaining structure, requiring us to accordingly monitor the deformation of the flexible retaining structure in order to prevent dam collapse from bringing devastation to the downstream. The maximum deformation position is located in the middle of the flexible retaining structure, which gradually decreases to both sides. The support cable plays an obvious role in restraining the flexible retaining net and acts as a major carrier in bearing and transmitting force. The results of numerical simulation are compared with the deformation of real flexible retaining structure, showing good consistence.

In this article, the terrain conditions are simplified, considering neither the impact of the unevenness of the movement path on the motion characteristics of the debris flow and the dynamic characteristics of the flexible retaining structure nor the impact of the loose accumulation layer on the movement path on the impulsive force of the debris flow and the dynamic characteristics of the flexible retaining structure. All the abovementioned problems are the research difficulties and can be further studied in future research.

\section{Conclusion}

(1) Based on the coupling numerical method, this article considers the complex dynamic interaction of particle-fluid-structure, reproducing the whole process of flexible retaining structure impacted by debris flow, such as impact, retaining, water-rock separation, climbing, siltation, and deposition.

(2) We compare the dynamic response analysis of flexible retaining structure impacted by debris flow under different slopes, monitoring the displacement change of the middle position of four support cables (NO.1, NO.2, NO.3, and NO.4) of flexible retaining structure over time. It can be found that the simulation results and laws are consistent with the existing research results.

(3) We compare the change law of the impulsive force of debris flow under different slopes. However, the empirical formula does not consider the water-rock separation and the complex dynamic interaction of particle-fluid-structure, and thus, the error of empirical formula results and the numerical simulation results ranges from $12.1 \%$ to $27.4 \%$. As a result, the numerical analysis method is more reasonable than the empirical method.

(4) We analyze the maximum deformation of the flexible retaining structure, concluding that the deformation is positively associated with the slope of the channel. The maximum deformation is located in the middle of the flexible retaining structure, and the support cable can obviously restrain the flexible retaining net.

\section{Data Availability}

The data for this study are available on request to the corresponding author.

\section{Conflicts of Interest}

The authors declare that there are no conflicts of interest regarding the publication of this paper.

\section{Acknowledgments}

This research was funded by the Natural Science Foundation of China (grant no. 41972267).

\section{References}

[1] J. L. Miao, W. Z. Zhang, and J. Y. Zhou, "Numerical simulation of the accumulation state of viscous debris flow by smooth particle hydrodynamics method," Journal of Natural Disasters, vol. 22, no. 6, pp. 125-130, 2013. 
[2] M. Jakob, O. Hungr, and D. M. Jakob, "Debris-flow hazards and related phenomena," Environmental and Engineering Geoscience, vol. 8, no. 1, pp. 165-171, 2007.

[3] C. A. Dowling and P. M. Santi, "Debris flows and their toll on human life: a global analysis of debris-flow fatalities from 1950 to 2011," Natural Hazards, vol. 71, no. 1, pp. 203-227, 2014.

[4] C. Tang, N. Rengers, T. W. J. van Asch, Y. H. Yang, and G. F. Wang, "Triggering conditions and depositional characteristics of a disastrous debris flow event in Zhouqu city, Gansu province, northwestern China," Natural Hazards and Earth System Sciences, vol. 11, no. 11, pp. 2903-2912, 2011.

[5] W. Ashwood and O. Hungr, "Estimating total resisting force in flexible barrier impacted by a granular avalanche using physical and numerical modeling," Canadian Geotechnical Journal, vol. 53, no. 10, pp. 1700-1717, 2016.

[6] C. W. W. Ng, D. Song, C. E. Choi, L. H. D. Liu, and J. S. H. Kwan, "Impact mechanisms of granular and viscous flows on rigid and flexible barriers," Canadian Geotechnical Journal, vol. 54, no. 2, pp. 188-206, 2016.

[7] T. Haas, L. Braat, J. R. Leuven, I. R. Lokhorst, and M. G. Kleinhans, "Effects of debris flow composition on runout, depositional mechanisms, and deposit morphology in laboratory experiments," Journal of Geophysical Research: Earth Surface, vol. 120, no. 9, pp. 19493-1972, 2015.

[8] X. B. Zhou, Debris Flow's Harm to Bridge Engineering and its Prevention, Tongji University, Shanghai, China, 2006.

[9] Z. Tao, M. Li, C. Zhu, M. He, X. Zheng, and S. Yu, "Analysis of the critical safety thickness for pretreatment of mined-out areas underlying the final slopes of open-pit mines and the effects of treatment," Shock and Vibration, vol. 2018, no. 2, pp. 1-8, 2018.

[10] X. J. Yang, J. M. Wang, C. Zhu, M. C. He, and Y. Gao, "Effect of wetting and drying cycles on microstructure of rock based on SEM," Environmental Earth Sciences, vol. 78, no. 6, pp. 1866-6280, 2019.

[11] Z. Liang, C. Wang, D. Ma, and K. U. J. Khan, "Exploring the potential relationship between the occurrence of debris flow and landslides," Natural Hazards and Earth System Sciences, vol. 21, no. 4, pp. 1247-1262, 2021.

[12] L. Ban, C. Zhu, C. Qi, and Z. Tao, "New roughness parameters for 3D roughness of rock joints," Bulletin of Engineering Geology and the Environment, vol. 78, no. 6, pp. 4505-4517, 2019.

[13] C. Zhu, K. Zhang, H. Cai et al., "Combined application of optical fibers and CRLD bolts to monitor deformation of a pitin-pit foundation," Advances in Civil Engineering, vol. 2019, no. 1, 16 pages, Article ID 2572034, 2019.

[14] A. Leonardi, F. K. Wittel, M. Mendoza, and J. Herrmann, "Multiphase debris flow simulations with the discrete element method coupled with a lattice-Boltzmann fluid," in Proceedings of the III International Conference on Particle-based Methods Fundamentals and Applications, pp. 276-287, Stuttgart (Germany), 2013.

[15] A. Armanini, "On the dynamic of debris flows," Recent Development on Debris Flows, pp. 208-226, Springer, Heidelberg, Germany, 1997.

[16] C. Lichtenan, Die berechnung von sperren in beton und eisenbeton, kolloquium on torrent dams odc 384.3, pp. 91-127, Mitteilungen der Forstlichen Bundes-Versuchsanstalt, Wien, 1973.

[17] A. Albaba, S. Lambert, F. Kneib, B. Chareyre, and F. Nicot, "DEM modeling of a flexible barrier impacted by a dry granular flow," Rock Mechanics and Rock Engineering, vol. 50, no. 11, pp. 3029-3048, 2017.
[18] W. Anthony, G. Laurence, and V. Guillaume, "Grains3D, a flexible DEM approach for particles of arbitrary convex shape part I: numerical model and validations," Powder Technology, vol. 224, pp. 374-389, 2012.

[19] C. Scheidl, M. Chiari, R. Kaitna et al., "Analysing debris-flow impact models, based on a small scale modelling approach," Surveys in Geophysics, vol. 34, no. 1, pp. 121-140, 2013.

[20] Z. Tao, H. Zhang, C. Zhu, Z. Hao, X. Zhang, and X. Hu, "Design and operation of App-based intelligent landslide monitoring system: the case of Three Gorges Reservoir Region," Geomatics, Natural Hazards and Risk, vol. 10, no. 1, pp. 1209-1226, 2019.

[21] Z. G. Tao, C. Zhu, M. C. He, and K. M. Liu, "Research on the safe mining depth of anti-dip bedding slope in Changshanhao Mine," Geomechanics and Geophysics for Geo-Energy and GeoResources, vol. 36, no. 6, pp. 1-20, 2020.

[22] Z. Liang, C.-M. Wang, Z.-M. Zhang, and K.-U.-J. Khan, "A comparison of statistical and machine learning methods for debris flow susceptibility mapping," Stochastic Environmental Research and Risk Assessment, vol. 34, no. 11, pp. 1887-1907, 2020.

[23] Z. Tao, Q. Geng, C. Zhu et al., "The mechanical mechanisms of large-scale toppling failure for counter-inclined rock slopes," Journal of Geophysics and Engineering, vol. 16, no. 3, pp. 541-558, 2019.

[24] A. Leonardi, F. K. Wittel, M. Mendoza, R. Vetter, and H. J. Herrmann, "Particle-fluid-structure interaction for debris flow impact on flexible barriers," Computer-Aided Civil and Infrastructure Engineering, vol. 31, no. 5, pp. 323-333, 2016.

[25] A. Leonardi, F. K. Wittel, M. Mendoza, and J. Hans, "Multiphase debris flow simulations with the discrete element method coupled with a lattice-Boltzmann fluid," in Proceedings of the III International Conference on Particle-based Methods Fundamentals and Applications, pp. 276-287, Stuttgart (Germany), 2013.

[26] A. Leonardi, F. K. Wittel, M. Mendoza, and H. J. Herrmann, "Lattice-Boltzmann method for geophysical plastic flows," Recent Advances In Modeling Landslides And Debris Flows, pp. 131-140, Springer, Cham, Switzerland, 2015.

[27] A. Leonardi, F. K. Wittel, M. Mendoza, and H. J. Herrmann, "Coupled DEM-LBM method for the free-surface simulation of heterogeneous suspensions," Computational Particle Mechanics, vol. 1, no. 1, pp. 3-13, 2014.

[28] X. Li and J. Zhao, "A unified CFD-DEM approach for modeling of debris flow impacts on flexible barriers," International Journal for Numerical and Analytical Methods in Geomechanics, vol. 42, no. 14, pp. 1643-1670, 2018.

[29] X. Li and J. Zhao, "Dam-break of mixtures consisting of nonNewtonian liquids and granular particles," Powder Technology, vol. 338, pp. 493-505, 2018.

[30] C. Liu, Z. Yu, and S. Zhao, "Quantifying the impact of a debris avalanche against a flexible barrier by coupled DEM-FEM analyses," Landslides, vol. 17, no. 1, pp. 33-47, 2020.

[31] C. Liu, Z. X. Yu, and L. R. Luo, "Dynamic behavior of a concrete dam impacted by debris flows with rock," Journal of Vibration and Shock, vol. 38, no. 14, pp. 161-168, 2019.

[32] B. Li, C. Wang, Y. Li et al., "Dynamic response analysis of retaining dam under the impact of solid-liquid two-phase debris flow based on the coupled SPH-DEM-FEM method," Geofluids, vol. 2020, Article ID 6635378, 12 pages, 2020.

[33] H.-k. Chen, H.-m. Tang, and Y.-i. Chen, "Research on method to calculate velocities of solid phase and liquid phase in debris 
flow," Applied Mathematics and Mechanics, vol. 27, no. 3, pp. 399-408, 2006.

[34] Q.-X. Meng, W.-Y.Xu, H.-L. Wang, X.-Y. Zhuang, W.-C. Xie, and T. Rabczuk, "DigiSim - an open source software package for heterogeneous material modeling based on digital image processing," Advances in Engineering Software, vol. 148, Article ID 102836, 2020.

[35] C. Zhu, M.-c. He, M. Karakus, X.-h. Zhang, and Z. Guo, "The collision experiment between rolling stones of different shapes and protective cushion in open-pit mines," Journal of Mountain Science, vol. 18, no. 5, pp. 1391-1403, 2021.

[36] Q. Yin, J. Y. Wu, C. Zhu et al., "Shear mechanical responses of sandstone exposed to high temperature under constant normal stiffness boundary conditions," Geomechanics and Geophysics for Geo-Energy and Geo-Resources, vol. 7, no. 2, 2021.

[37] W. Wang, G. Chen, Z. Han, S. Zhou, H. Zhang, and P. Jing, "3D numerical simulation of debris-flow motion using SPH method incorporating non-Newtonian fluid behavior," Natural Hazards, vol. 81, no. 3, pp. 1981-1998, 2016.

[38] Q. Wang, Z. Jiang, B. Jiang, H. Gao, Y. Huang, and P. Zhang, "Research on an automatic roadway formation method in deep mining areas by roof cutting with high-strength boltgrouting," International Journal of Rock Mechanics and Mining Sciences, vol. 128, Article ID 104264, 2020.

[39] Y. Wang, W. K. Feng, R. L. Hu, and C. H. Li, "Fracture evolution and energy characteristics during marble failure under triaxial fatigue cyclic and confining pressure unloading (FC-CPU) conditions," Rock Mechanics and Rock Engineering, vol. 54, no. 2, pp. 799-818, 2021.

[40] Q. Wang, Y. Wang, M. He et al., "Experimental research and application of automatically formed roadway without advance tunneling," Tunnelling and Underground Space Technology, vol. 114, no. 3, Article ID 103999, 2021.

[41] F. Wu, R. Gao, J. Liu, and C. Li, "New fractional variable-order creep model with short memory," Applied Mathematics and Computation, vol. 380, Article ID 125278, 2020.

[42] F. Wu, H. Zhang, Q. Zou, C. Li, J. Chen, and R. Gao, "Viscoelastic-plastic damage creep model for salt rock based on fractional derivative theory," Mechanics of Materials, vol. 150, Article ID 103600, 2020.

[43] A. Li, F. Dai, Y. Liu, H. Du, and R. Jiang, "Dynamic stability evaluation of underground cavern sidewalls against flexural toppling considering excavation-induced damage," Tunnelling and Underground Space Technology, vol. 112, Article ID 103903, 2021.

[44] J. S. H. Kwan, "Supplementary technical guidance on design of rigid debris-resisting barriers," Geotechnical Engineering Office, Civil Engineering Dept, Chennai, India, 2012. 